\title{
Subsistence Strategies and Burial Rituals: Social Practices in the Late Deccan Chalcolithic
}

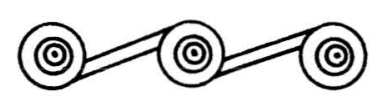

TERESA P. RACZEK

IN THE SECOND MILLENNIUM B.C., THE RESIDENTS OF THE WESTERN DECCAN region of India practiced an agropastoral lifestyle and buried their infant children in ceramic urns below their house floors. With the coming of the first millennium B.C., the inhabitants of the site of Inamgaon altered their subsistence practices to incorporate more wild meat and fewer grains into their diet. Although daily practices in the form of food procurement changed, infant burial practices remained constant from the Early Jorwe (1400 B.C. -1000 B.C.) to the Late Jorwe (1000 B.C. -700 B.C.) period. Examining interments together with subsistence strategies firmly situates ideational practices within the fabric of daily life.

This paper will explore the relationship between change and continuity in burial and subsistence practices around 1000 B.C. at the previously excavated Chalcolithic site of Inamgaon in the western Deccan (Fig. 1). By considering the act of burial as a moment of social construction that both creates and reflects larger traditions, it is possible to understand how each individual interment affects chronological variability. That burial traditions at Inamgaon were continuously recreated in the face of a changing society suggests that meaningful and significant practices were actively upheld. Burial practices at Inamgaon were both structured and fluid enough to allow room for individual and group expression. The contemporaneous variability that occurs in the burial record at Inamgaon may reflect the marking of various aspects of personhood. Burial traditions and the ability and desire of the living to conform to them vary over time and it is important to consider the specific social context in which they occur. This paper will first discuss various theories proposed to explain changes in subsistence strategies at Inamgaon and then examine chronological and contemporaneous variation of burial remains at that site.

This paper mainly deals with burials in the western Deccan, the region between the Godavari River and Krishna River and east of the Western Ghats. This region has also been variously referred to as the Deccan (Dhavalikar 1979; Panja 2002; Shinde 1994) and the northern Deccan (Parasher and Rai 1984), although

Teresa P. Raczek is a graduate student in the Department of Anthropology, University of Pennsylvania, Philadelphia.

Asian Perspectipes, Vol. 42, No. 2 (r) $2(0) 3$ by University of Hawai i l'ress. 


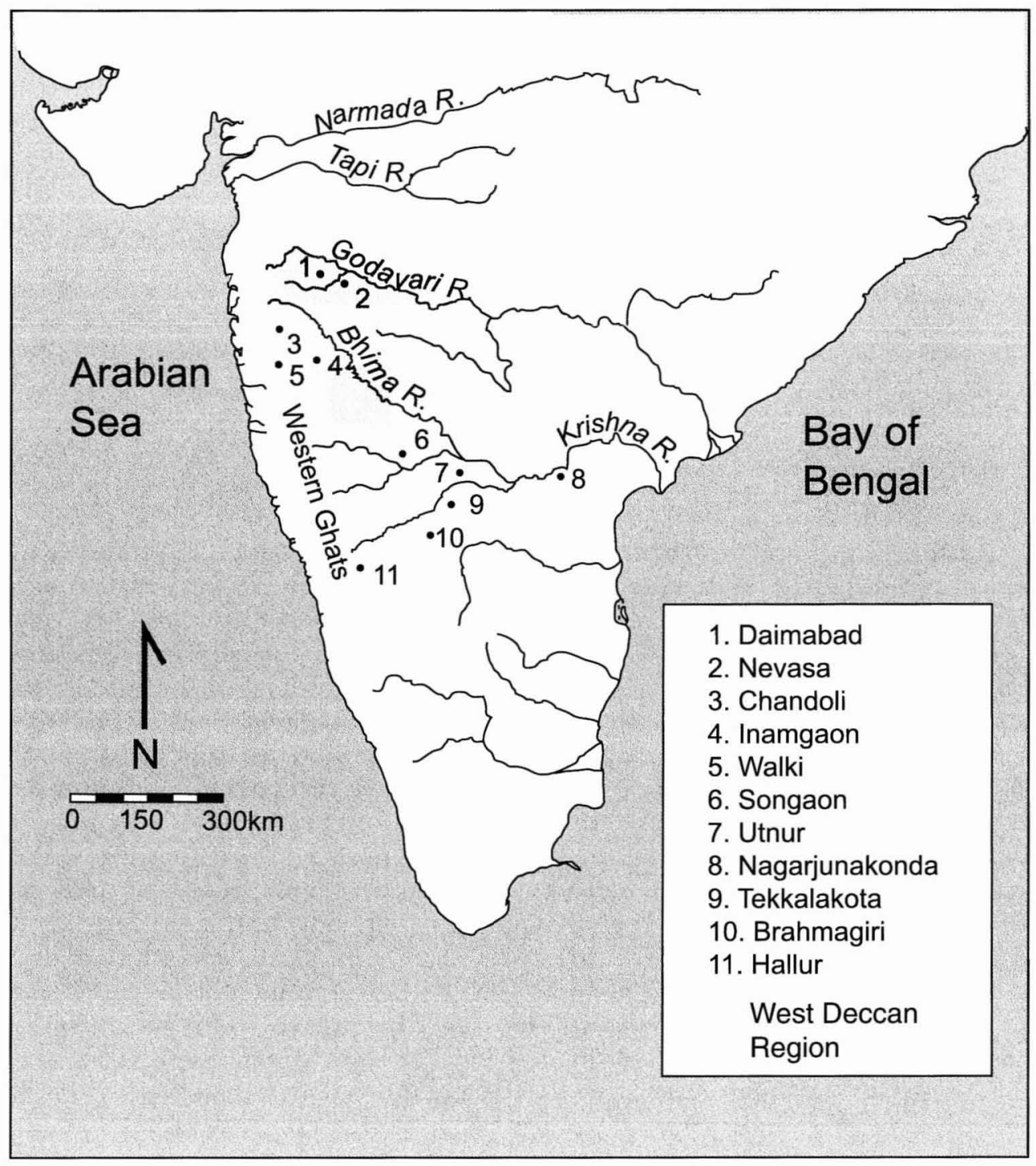

Fig. 1. Map of region.

some simply locate the region within the contemporary state of Maharashtra (Chakrabarti 1999). Although infant urn burials occurred at sites in the south at this time, the traditions differ slightly from the western Deccan, and there appears to be more variation between southern sites. Infants in the western Deccan were largely buried in two ceramic urns placed mouth to mouth horizontally, infants to the south were interred in a variety of different ways: in single and double urns placed horizontally or vertically, in bowls, or directly in the earth. Thus, the southern Deccan will not be considered in this analysis. 


\section{SOCIAL PRACTICE, BURIALS, AND THE ROLE OF AGENCY}

Subsistence activities, like farming and herding, are performed daily by individuals and groups who act with knowledge of multiple intersecting traditions (Barrett 2000). While these daily practices are molded by larger traditions, the reverse is also true. That is, the relationship is recursive (Giddens 1984). This process occurs every day in every action (Bourdieu 1977). Directed action may seek change or continuity, but the consequences of these actions may not have been anticipated. In subsistence practices then, daily decisions on the individual or group level about planting, harvesting, or moving herds, may re-enact traditions or create new ones. Transformations of subsistence practices occur in the context of climate change, technological innovation, the appearance of new neighbors, and a variety of other factors, each of which has the potential to influence daily decision making.

Burial of the dead differs greatly from many other social practices, since these acts occur at socially significant moments and are not usually performed daily (Metcalf and Huntington 1991). While participants in burial rituals draw from a standard set of practices regarding the treatment and placement of the body, they also personalize the funeral and interment, selecting and rejecting particular elements. The resulting ritual influences future burials by confirming some procedures as socially standard and others as variant. Burial rituals that persist over long periods of time reflect repeated confirmation of these traditions. That is, like change, continuity in practices must be produced through repetitive action (Cowgill 2000:57).

\section{MORTUARY ANALYSIS}

While the skeletal remains from the second millennium B.c. in the west Deccan region have been well studied, burials as cultural features have received less attention. The major exception is the work of Dhavalikar and Ansari (1988c) who, in their analysis at Inamgaon, drew largely from Binford's discussions of marked status. In a seminal article that has been much debated, Binford (1971) argued that mortuary remains reflect age, sex, social status, and affiliation of the deceased, as well as cause and location of death. Status, Binford (1971:23) suggested, was marked in many ways including burial location, preparation of the body, and inclusion of, "large quantities of contributed goods." Ethnic affiliation, gender, age, occupation, or other identities can also be marked by the living who place material items in the grave for this purpose (O'Shea 1981). Unfortunately, some mortuary analyses do not take into account the overlapping nature of personal identities within a single person. As roles, identities, and group memberships intersect, the practices associated with each of these will vary and affect treatment at death (Chapman 2000:173; Gillespie 2001). Contemporaneous intrasite variability of burials should be examined carefully using a concept of "personhood" that incorporates overlapping roles and identities into an understanding of the individual and not simply status as measured by wealth.

Burials are not passive reflections of the social status and social roles held by the deceased (Parker Pearson 1999). Instead, burials are actively performed by the 
living who have larger goals. Through burials, the living demonstrate their wealth and power as well as political and social goals as they wish the larger community to understand them (Parker Pearson 1999). Subtle differences between burials, as detected by archaeologists, reflect the choices of those who inter the body and the messages they wish to convey, including both the constitution and contestation of social norms (Barrett 1996). While aspects of personhood may be marked as a byproduct of these actions, they can also be concealed, exaggerated, or selectively chosen.

The specifics of burial practices vary according to locality even if they may generally follow a wider regional structure. Local implementation of regional burial traditions occurred across the west Deccan and in regions to the south during the second millennium B.C. Infant burial practices throughout the south Deccan Neolithic were locally defined and related to regional traditions. Urn burials were found at many sites, including Brahmagiri (Wheeler 1948), Hallur (Nagaraja Rao 1971), Nagarjunakonda (Subrahmanyam 1975), Palavoy (Rami Reddy 1976), Tekkalakota (Nagaraja Rao and Malhotra 1965; Sankalia 1964), Tekwada (IAR 1957:18-19), and Watgal (Devaraj et al. 1995). Occasionally (as at Brahmagiri, Watgal, and Palavoy), the urns were interred vertically, such that one sat on top of the other. In some of these vertical twin-urn burials, both urns faced up and the base of the top urn capped the mouth of the underlying urn that held the infant. In each of these cases regional burial traditions were enacted in locally appropriate ways. While some local variation of regional burial traditions also occurred in the west Deccan region, the burials of these sites seem to share more features than burials from sites to the south.

Burial rituals are opportunities for societies to confirm or contest beliefs about death and life, as well as the social order and each person's place within it. By performing burial rites in socially prescribed ways, surviving members of society-family, neighbors, or other representatives of the deceased's community-show support for upholding social structures. In this conception of burial as social practice, chronological continuity, such as can be seen among infant burials at Inamgaon, is seen as an endorsement of social structure, and chronological change is seen as a reframing of social understandings.

\section{INFANT BURIALS}

With some exceptions, most theoretical approaches to mortuary rituals developed as a means to understand adult burials. However, it is clear that various age groups are treated differently in death as they are in life. Specific divisions between age groups, such as neonate, infant, subadult, and adult, used in burial analysis are constructs offered by physical anthropologists who refer to biological developmental levels, with boundaries that are contested and difficult to define (Buikstra and Konigsberg 1985; Konigsberg and Frankenberg 1994). The age estimates at Inamgaon were listed as ranges within a few months or years, with the exception of highly decayed bones, which were designated perinatal or infant. Such age groups are not easily applied on a theoretical level since they do not necessarily coincide with cultural divisions between age-grades (see also Clark, this volume). In addition, the division between each age group may or may not be recognized in the burial process. 
Among many societies, infants are not recognized as fully human or as part of the family or larger social group until a certain age, whether that is measured in days, months, or by the passing of milestones such as weaning (McHugh 1999:19), the ability to speak, or participation in a specific ritual. Some have argued (Scheper-Hughes 1992) that the phenomenon of recognizing children sometime after birth can be attributed to high rates of infant mortality; only infants who survive for a given time period are worthy of acceptance by society. As a result, those who die before the prescribed time period has passed may receive less attention since they are unimportant (Hertz 1960), or more attention, for any number of reasons (McHugh 1999). Infant corpses, then, may be treated differently or buried in a different location or position than adults. In the western Deccan region infants comprise the overwhelming majority of Chalcolithic burials and they are buried in a different manner from adults. This indicates that the concept of infants as a distinct age group existed and influenced the burial process.

Each grave records the actions of those who placed the burial and can be considered indicative of human agency. The selection of the grave site, the coffin, and grave goods, as well as the placement of the body, together and individually, represent multiple choices by those who bury, as they negotiate between their understanding of social standards and their means and desire to adhere to them. When investigated as a collection, it is possible to see in burials a standardized set of practices as well as variation that offers a glimpse of the individual person in the archaeological record. More importantly, by contrasting commonalities with variation among a burial population we can see which features were considered important enough to conserve as tradition.

\section{THE DECCAN CHALCOLITHIC}

The Chalcolithic period in the west Deccan region roughly spans $1600-700$ B.C. and is traditionally divided into three phases based on a combination of ceramic typology and radiocarbon dating from the site of Inamgaon (Ansari 1988): Malwa (1600 B.C. -1400 B.c.); Early Jorwe (1400 B.C. -1000 B.C.); and Late Jorwe (1000 B.C. -700 в.с.). While dividing large expanses of time into periods aids examination of continuity and change in a given region, it is important to keep in mind that the dividing dates-1400 B.C. and 1000 B.C.- - are approximate and fluid. It has been suggested that ceramic types in the region changed gradually (Shinde 1994:173) and thus, the periods based on this typology must be seen as flexible rather than absolute.

The Chalcolithic inhabitants of the west Deccan region practiced agriculture and pastoralism, as well as hunting and fishing. Five large mounded sites have been identified in this region as well as several smaller sites and hundreds of lithic scatters that are presumed to be from the same time period (Deo 1969; Naik and Mishra 1997; Sali 1986; Shinde 1989). Daimabad, the largest of the sites, is considered to be a regional center, and Inamgaon a more localized center for smaller sites like Nevasa and Chandoli (Dhavalikar 1985; Shinde and Pappu 1990). People in this semistratified society practiced local and long-distance trade; imported goods included marine shells from both the east and west, minerals, and metals (Dhavalikar 1985). Copper items in the form of chisels, spearheads, fishhooks, 
pins, and beads have also been found at many sites (Shinde 1990). The people of the Deccan continued to rely heavily on lithics throughout the Chalcolithic period, manufacturing blades from local chalcedony, chert, and other cryptocrystalline materials. Pottery, largely wheel-thrown, was fired in kilns and in surface burns. Personal adornments included stone and copper bangles, and beads made of copper, shell, steatite, carnelian, agate, and other stones.

\section{REGIONAL BURIAL PRACTICES}

\section{Adults}

While more common in the southern Neolithic (2700-1000 B.C.), adult burials in the western Deccan Chalcolithic are infrequent. Adult burials are found at Daimabad (one extended burial in the Jorwe period), Chandoli (one extended burial in the earliest Chalcolithic habitation), Nevasa (one), Walki (one with two carinated bowls and a spouted vessel at 1300-1200 в.с.) and Inamgaon (see below). Adults at these sites were usually buried in an extended north-south position, sometimes with grave goods similar to those interred with infants. The only adult skeleton recovered from Chandoli has disarticulated lower legs (Deo and Ansari $1965: 18$ ), as do adult skeletons from Daimabad (Kennedy and Malhotra 1966:127), Walki (Mushrif and Walimbe 2000:21) and Inamgaon (Dhavalikar and Ansari 1988c). Inamgaon seems to be the only site where adult burials increased over time, a change that largely occurred between the Malwa and Jorwe periods.

\section{Infants and Children}

While adult burials are rare, infant burials are common throughout the region and have been found at Chandoli (Deo and Ansari 1965), Nevasa (Sankalia et al. 1960), Songaon (Deo 1969), Daimabad (Sali 1986), Walki (Dhavalikar et al. 1990; Mushrif and Walimbe 2000), and Tuljapur Garhi (Bopardikar 1996; Walimbe 1996) (Table 1). At all of these sites, except Tuljapur Garhi, infants were interred in single or twin ceramic urns. Single-urn burials consist of one ceramic urn that lies horizontally or vertically and may be capped with a small ceramic vessel. The twin-urn burials are usually located under house floors and lie horizontally in a north-south direction with the infant's head in the northern pot. Some burials include grave goods in the form of ceramic vessels or beads. Ceramic vessels,

Table i. Burials in the Western Deccan

\begin{tabular}{|c|c|c|c|c|c|}
\hline & $\begin{array}{l}\text { SINGLE-URN } \\
\text { BURIALS }\end{array}$ & $\begin{array}{c}\text { DOUBLE-URN } \\
\text { BURIALS }\end{array}$ & $\begin{array}{c}\text { MULTIPLE-URN } \\
\text { BURIALS }\end{array}$ & $\begin{array}{c}\text { TOTAL URN } \\
\text { BURIALS }\end{array}$ & $\begin{array}{c}\text { ADULT } \\
\text { BURIALS }\end{array}$ \\
\hline Chandoli & 3 & 19 & 1 & 23 & 1 \\
\hline Daimabad & 2 & 32 & 1 & $35 \star$ & 1 \\
\hline Nevasa & 0 & 18 & 0 & 4 & 1 \\
\hline Walki & 4 & 9 & 0 & 13 & 2 \\
\hline Songaon & 1 & 2 & 0 & 3 & 0 \\
\hline
\end{tabular}

^ This number represents urns with skeletal remains that could be studied. In total 71 burials were recovered from Daimabad during the Malwa and Jorwe phases, but the site report does not give totals of each type except for those skeletons that were studied. 
placed inside the burial urns or next to the urns in the grave pit, usually consist of carinated bowls or spouted vessels. Beads generally lie in the neck region and are made of copper, pearl, carnelian, or other stones.

Children (noninfant subadults) were rarely buried within the settlement area. Those who were are generally found placed in an extended north-south position. Families occasionally interred children in burial urns, and used more than two in order to accommodate the entire body. In these cases, the base of the middle urn was broken out, which allowed the body to pass through. Single instances of three-urn burials have been found at Daimabad in the Jorwe (Sali 1986:168), Chandoli in the Jorwe (Deo and Ansari 1965:18), at Nevasa in Period III of the Chalcolithic (Sankalia et al. 1960:23), and Songaon in the Malwa (Deo 1969:6), while three such burials were found in Late Jorwe levels at Inamgaon (Dhavalikar and Ansari 1988c).

The excavators at Chandoli found that the number of burials decreased over time with the greatest number of burials (eleven) in the earliest occupation of the site, and the fewest (three) in the latest occupation (Deo and Ansari 1965:17). While it is possible to explain the decrease in infant burials from the Malwa to the Jorwe periods by a decrease in infant mortality rates, it is unlikely that rates changed that dramatically. This sample size is very small, but suggestive. We can infer then, that the practice of interring infants in urns faded during the Jorwe period at Chandoli and that the inhabitants began to treat the infants in different (archaeologically undetectable) ways. Nevasa was abandoned at approximately the same time as Inamgaon and later occupants did not bury infants on site. Although data from other sites is limited due to smaller excavation areas and an emphasis on stratigraphic excavation, the pattern at these two Deccan Chalcolithic sites contrasts with that of Inamgaon. As the inhabitants of Chandoli discarded the practice of urn burials, those at Inamgaon actively preserved it.

\section{INAMGAON}

The most intensely studied site of the west Deccan Chalcolithic is the site of Inamgaon, located on the Ghod River, a tributary of the Bhima River, in the Pune District of Maharashtra, India. Employing a horizontal excavation strategy, a team from Deccan College led by Dhavalikar, Sankalia, and Ansari investigated human-environment relationships at this site. Over the course of twelve seasons (1969 to 1982) the team produced a wealth of data that continue to inform researchers interested in the Deccan Chalcolithic (Dhavalikar et al. 1988).

Unlike most other excavated sites in the Deccan, which do not show evidence of occupation in the Late Jorwe (Naik and Mishra 1997), Inamgaon was occupied during all three periods of the Chalcolithic, and so the site offers the opportunity to explore long-term change. Faunal, botanical, ceramic and spatial analyses all point to major transformations at approximately 1000 B.C., the transition between the Early and Late Jorwe. Dhavalikar $(1979,1984,1985,1988)$ argued that the entire region was abandoned around this time in response to the onset of a significantly drier climate but that Inamgaon remained inhabited for another 300 years (for a discussion on climate see Kajale et al. 1976; Kale and Rajaguru 1987; Krishnamurthy et al. 1981). He suggested that subsistence strategies in the Late Jorwe at Inamgaon shifted from settled agriculturalism to mobile pastoralism 
based on three main factors. First, the original faunal analysis showed a shift from cattle to goat consumption. Second, examination of the ethnobotanical remains and analyses of human osteological strontium indicated a decrease in grain consumption. Finally, a concomitant change in house shape was interpreted to indicate a new preference for constructing expedient houses. Shinde and others (Dhavalikar et al. 1990; Shinde 1988, 1989, 1994) have supported this thesis through the investigation of smaller sites such as Walki, where parallel changes in material culture occurred during this time. Further, Naik and Mishra (1997) argued that as part of the overall changes in subsistence strategy in the Late Jorwe, settlements shrank in size and were inhabited for shorter periods of time.

More recently, Panja (1999) developed an alternative theory of the subsistence strategies at Inamgaon and nearby sites. Panja's study drew from a re-analysis of the Inamgaon faunal remains by Pawankar (1996 in Panja 1999), which reclassified many sheep and goat bones as deer. This new analysis indicated an increase in the consumption of wild game in the Late Jorwe, rather than sheep and goats as previously understood. Drawing from multiple lines of evidence, Panja concluded that the inhabitants of the region employed a semimobile, agropastoral subsistence strategy in order to minimize the effects of regular, periodic drought conditions brought on by punctuated ineffective monsoon seasons. In contrast to Dhavalikar, Panja argued that Inamgaon and other nearby sites had only been inhabited seasonally throughout the entire Chalcolithic, not just during the Late Jorwe. In order to explain the increase of wild game consumption and simultaneous shift in architecture in the Late Jorwe, Panja $(1999,2002)$ postulated that the site was occasionally used by hunter-gatherer groups who either lived alongside the original agropastoral inhabitants or replaced them.

The residents of Inamgaon clearly ate fewer grains and more wild game at this time. This indicates a reduced reliance upon agriculture and an increased emphasis on hunting and gathering by the residents at Inamgaon. Intensifying trading activities with hunter-gatherer groups may have been a successful way to mitigate the negative effects of climate change on agriculture. Trade and interaction between hunter-gatherers and agriculturalists was not uncommon in South Asia at this time. Possehl (1976, 2002) has documented extensive interaction between such groups in the Indus region. Morrison (2002) has argued that huntergatherers were often well integrated into regional networks and cautions that they should not be essentialized as monolithic types. Instead, hunting and gathering should be considered one of many subsistence strategies that may be paired with other food procurement tactics and that incorporates various levels of social complexity, mobility, and interaction with practitioners of other subsistence strategies. Unfortunately, very little research has been done on hunter-gatherers in the western Deccan during the Chalcolithic, so it is difficult to say whether such groups were ethnically distinct and to what extent they interacted with agropastoral communities. Such research could help illuminate the nature of changes at Inamgaon, particularly the manner in which wild animals were obtained for consumption.

Research into subsistence has provided valuable insight into Deccan society as a whole and its connection to the environment. However, the relationship between changes in subsistence practices and mortuary practices have yet to be explored. Examining the burials at Inamgaon augments previous subsistence studies 
by offering a more complete picture of the persons who comprised Deccan society. The fixed nature of burial traditions contrasts with subsistence changes and may have offset dramatic changes in daily life.

\section{BURIALS AT INAMGAON}

According to Dhavalikar and Ansari (1988c:263), ${ }^{1}$ over 266 burials were recovered from Inamgaon: 23 from the Malwa period, 72 from the Early Jorwe period, and 171 from the Late Jorwe period. The disproportionately high number of burials in the Late Jorwe reflects the greater surface area excavated for the levels that represent that time period. There are three main types of burials at Inamgaon: single-urn, double-urn, and non-urn or pit burials (Fig. 2). Children and infants placed in single or double ceramic urns comprise the largest portion of the burials. There are, in addition, the three-urn burials, and burials in a large fourlegged unbaked storage jar. Similar to other sites, adult burials were usually laid out in an extended position and frequently the lower legs of adults were cut off and removed after death. Only some burials contain grave goods, usually in the form of pots and necklaces. The range of variation is discussed below.

Lukacs and Walimbe (1984; Lukacs and Badam 1976-1977) performed palaeopathological and population studies of 176 skeletons from Inamgaon and recently re-studied the teeth using new methodologies (Lukacs and Walimbe 1998). These researchers noted that there are few dental pathologies among the adults, but that localized hypoplasia of primary canine teeth (LHPC) occurs in infants and children (Lukacs and Walimbe 1998). ${ }^{2}$ LHPC is generally found among populations that are nutritionally stressed and is commonly found at prehistoric sites in South Asia (Lukacs et al. 2001:1165). In their study, Lukacs and Walimbe discovered a decline of LHPC between the Early and Late Jorwe, which they attributed to better nutrition arising from changes in subsistence practices in the later period. The authors argued that increased consumption of meat and decreased consumption of agricultural products in the Late Jorwe led to increased health in the general population (Lukacs and Walimbe 2000). They found no significant difference in LHPC rates between burial types (1998:582). ${ }^{3}$ This indicates that burial type most likely does not correspond to economic levels.

Dhavalikar and Ansari (1988c) conducted their mortuary analysis with a view toward understanding the political and economic structure of the site. Like Binford, these authors argued that differential treatment of the dead and the inclusion of high numbers of prestige goods indicated high social status and the possession of political power. They suggested that the Early and Late Jorwe burials associated with the largest house-a three-room structure with adjacent granariesincluded a chief (so designated because he was interred in a four-legged jar and his feet were not disarticulated) and his relatives (Dhavalikar and Ansari 1988a, 1988c). Some of these individuals were buried with several ceramic pots, and one was buried with a bead necklace. Dhavalikar and Ansari contend that these burials reflected the wealth of the household. However, some burials in the three-room "chief's" house contained few goods. Grave goods such as pots and necklaces are found across the site, not just in association with the chief's house. The individuals who placed goods with the body enacted their understanding of social traditions and had goals larger than (and possibly contrary to) the display of 


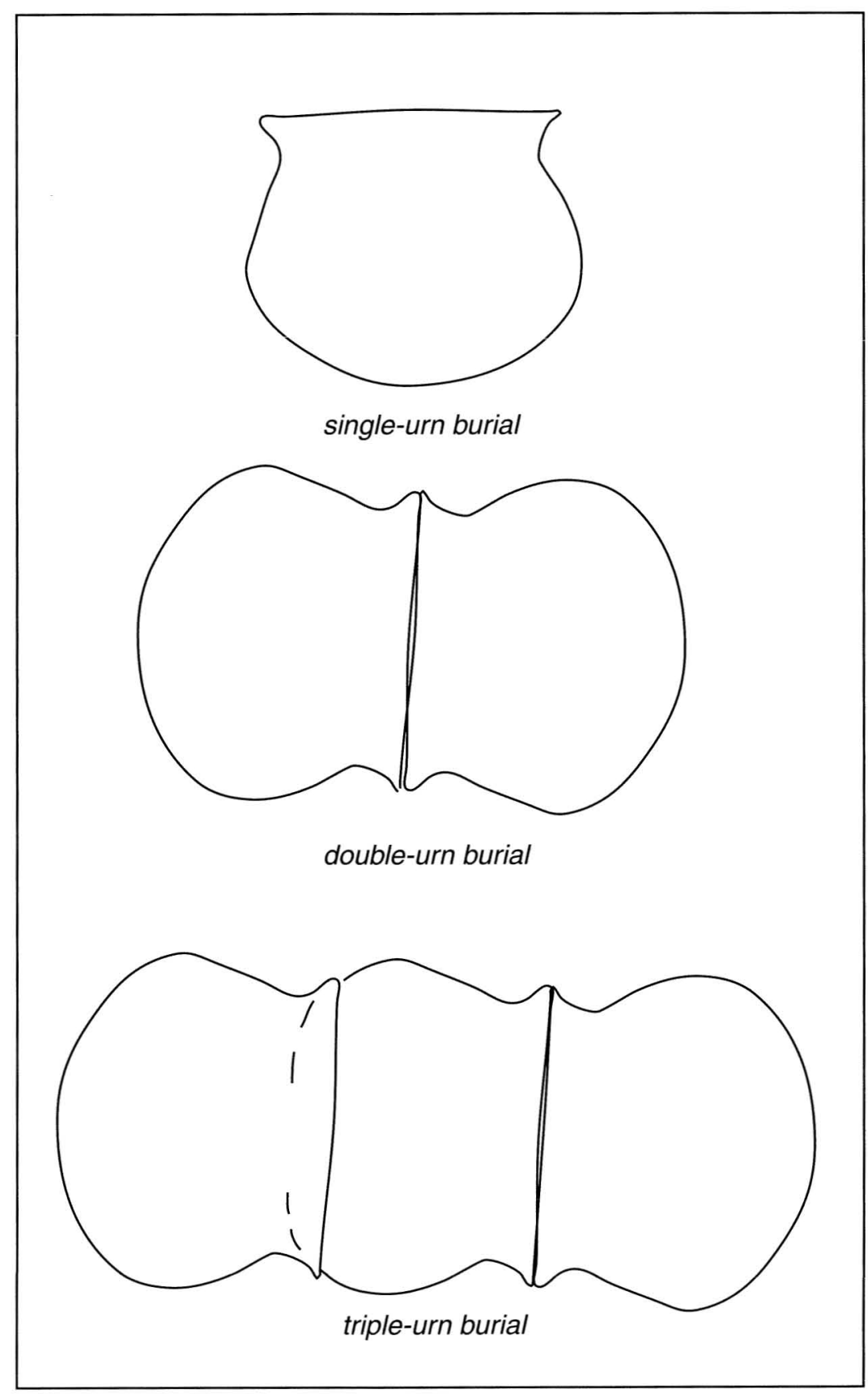

Fig. 2. Urn burial types.

wealth. For example, people may place many pots in the grave of one who earned great respect in the community through means other than wealth. Similarly, interment in a unique pot (such as the four-legged ones) and keeping the legs intact may mark some other important aspect of personhood other than 
wealth and political power. The deceased may have been a healer, religious figure, parented an unusual number of children, or been a potter. It is important to keep in mind that burial remains are the end product of a chain of decisions regarding ritual and that the practice of burial incorporates many different goalssome of which are related to personhood (like recognizing power) and some of which are not (like preservation of old traditions).

\section{A NEW CONSIDERATION OF BURIALS AT INAMGAON}

In reconsidering the burials at Inamgaon, this study examined chronological and contemporaneous variation. Given the substantial changes that occurred in subsistence practices and possibly attendant social organization and exchange, how can the changes in burial practices be best understood? This study also considered contemporaneous variability among burials as a way of illuminating expressions of personhood beyond the "chief/nonchief" division of society offered by earlier researchers. Toward this end, the records of 176 burials as presented in the site report from Inamgaon were studied (Dhavalikar and Ansari 1988c; Lukacs and Walimbe 1986). ${ }^{4}$ Type of burial (single-urn, twin-urn, non-urn or pit burial, and atypical), type and quantity of grave goods, body position, and postmortem removal of the lower extremities were all considered. When exact age ranges were provided in the site report, they were included in this analysis.

Urn burials were limited to children younger than 6 and a half, but non-urn burials included both children as young as $2-3$ years and adults. Thus, for children in the 2 to 6 -and-a-half year age range, age did not necessarily dictate the type of burial that was employed, unless some unidentified rite of passage occurred within this time frame. In the twin-urn category, the northern urn was usually larger and contained the skull or upper part of the child's body while the southern urn contained the lower half. In some cases the mouth of the smaller jar fit just inside the larger jar, creating a partial seal. Single- and twin-urn burials continued through all three periods at Inamgaon. Twin urns were preferred to singleurn burials and were only somewhat related to age or size of the deceased. That is, use of single urns was reserved for infants younger than 7-8 months but twin urns contained older and younger children, even fetuses. In sum, the type of infant burial-non-urn, single urn, or twin urn-only marginally relates to age. This indicates that other factors were at work as families made decisions regarding mortuary rituals. While marking aspects of personhood like gender or ethnic affiliation may be possible, it is also possible that each family simply interpreted the tradition of using urns for burials differently.

While a preference for twin-urn burials continued from the Early to the Late Jorwe period at Inamgaon, the type of ceramic selected for urns also seemed to persist. Burial urns in the Malwa period were generally made from Red/Gray Ware, which is also the most common ceramic (50-60 percent) in the entire assemblage at Inamgaon during the Malwa period (Dhavalikar and Ansari $1988 b: 358)$. While other ceramic types were introduced as burial urns in later periods, a preference for Red/Gray Ware burial urns continued. ${ }^{5}$ This preference contrasts directly with a marked decrease in Red/Gray Ware (20-28 percent) in the overall ceramic assemblage during the Late Jorwe (Dhavalikar and Ansari $1988 b$ : 494) (Fig. 3). The persistent use of Red/Gray Ware burial urns in the face 
Table 2. Types of Burials by Period

\begin{tabular}{|c|c|c|c|c|c|c|c|c|c|c|}
\hline & \multicolumn{2}{|c|}{$\begin{array}{l}\text { SINGLE } \\
\text { URN }\end{array}$} & TW & RN & \multicolumn{2}{|c|}{ TRIPLE } & \multicolumn{2}{|c|}{ NON-URN } & \multicolumn{2}{|c|}{$\begin{array}{l}\text { TOTAL } \\
\text { GRAVE } \\
\text { GOODS }\end{array}$} \\
\hline & $\mathrm{N}$ & $\%$ & $\mathrm{~N}$ & $\%$ & $\mathrm{~N}$ & $\%$ & $\mathrm{~N}$ & $\%$ & $\mathrm{~N}$ & $\%$ \\
\hline Malwa & 7 & 28 & 15 & 60 & 0 & 0 & 3 & 12 & 25 & 19 \\
\hline Early Jorwe & 3 & 4 & 38 & 55 & 0 & 0 & 29 & 41 & 70 & 24 \\
\hline Late Jorwe & 14 & 8 & 89 & 51 & 3 & 2 & 70 & 40 & 176 & 28 \\
\hline Total & 24 & & 142 & & 3 & & 102 & & 271 & \\
\hline
\end{tabular}

of changing ceramic styles in other contexts is noteworthy and demonstrates an active concern for continuity in this element of burial practice.

In contrast to the ceramics used as burial urns, those that constitute grave goods did change over time and generally mirrored the gradual changes that occurred in the ceramic assemblage found throughout the site. That is, as a given ceramic type, such as Malwa Ware, was discontinued in the greater ceramic assemblage, it was also discontinued as a grave good. Burials with ceramic grave goods usually included carinated bowls and spouted vessels although burials with large numbers of vessels included multiple pot forms. Some of these vessels contained faunal remains and one pot was coated in cooking soot (Dhavalikar and Ansari 1988c:317, 319). It is possible to infer that at least some pots included in these burials were everyday items used for cooking, eating, drinking, and other daily activities. They may have been previously used by the deceased, or selected from the family's current stock of ceramic goods. As material goods associated with common social practices, these grave goods reflected the changing styles of all ceramic goods used at Inamgaon.

The amount and type of grave goods varied between individuals. Most burials contained either no grave goods (about 72 percent) or one to three ceramic vessels, usually carinated bowls and spouted vessels (Fig. 4). However, some burials included other types of vessels and some, as discussed earlier, included as many as

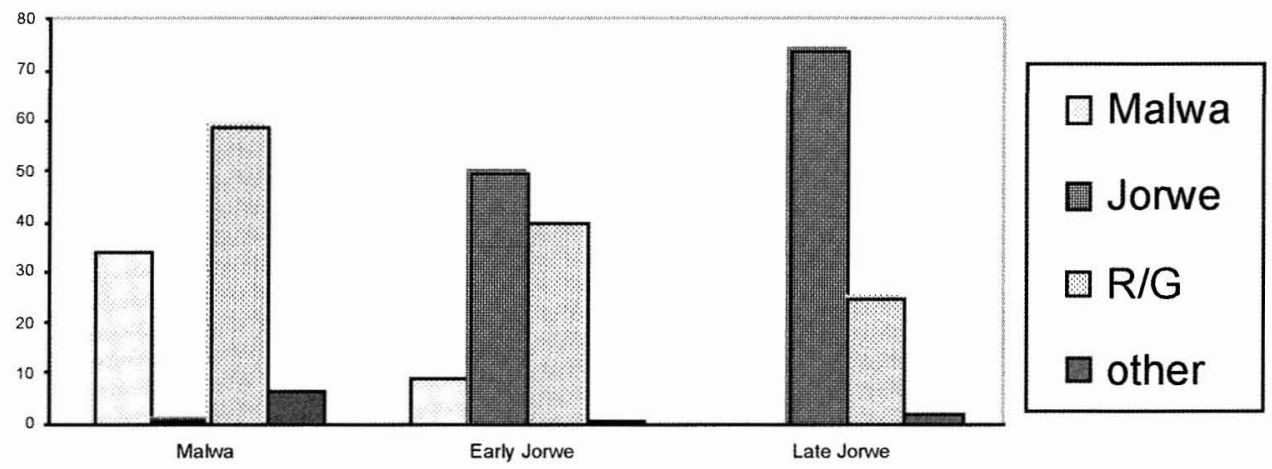

Fig. 3. Changes in ceramic assemblage. 


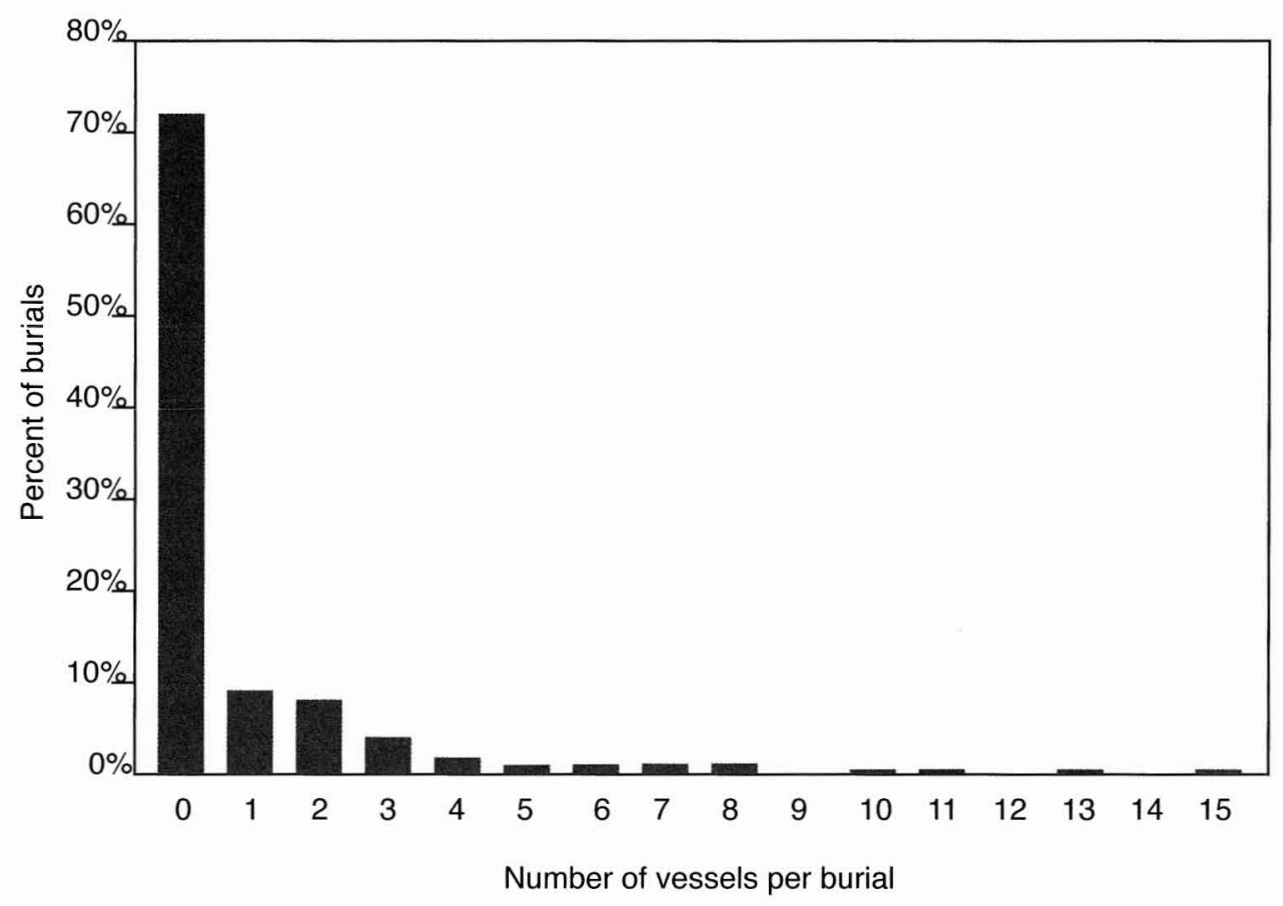

Fig. 4. Number of burials by vessel count per burial.

15 pots (Dhavalikar and Ansari 1988c:323, 333). The pots were either placed inside or outside the burial urns. Four individuals (all of them adults) were associated with pots that had boats painted on them (Dhavalikar and Ansari $1988 c: 292,296,317)$, which is one possible marker of personhood. One burial included an antler punch, another possible marker. Similarly, eight individuals were interred with beads of jasper, copper, shell, paste, or carnelian. As the family of the deceased prepared the body for interment, they included "appropriate" goods according to their means. Each family created their own definition of appropriate burial practices drawn from larger traditions, and implemented these practices according to their economic capacity. While these beads may have been luxury goods indicative of wealth, they were only included in burials when the family deemed it to be an appropriate practice. These decisions had to be made at the time of each burial.

In addition to variability among grave goods, there was sporadic deviation from the norm in terms of body orientation. Occasionally the upper body was placed in the southern urn instead of the northern urn. Some urns were laid in an east-west direction, instead of north-south. A small number of twin-urn burials consisted of urns made of two different fabrics instead of one material for both pots. These expressions were not all located in the same burial. That is, each burial followed the social norm in some way. For example, body orientation in a given burial may have been north-south, but each of the two urns were made of different ceramic materials. While social norms were consistently affirmed over time, there were also instances of nonstandard individual, family, or group 
expression. Similar to the inclusion of goods in the grave, these expressions also reflected each family's understanding of larger burial traditions and a desire to enact them. This variability in expression is consistent over time at Inamgaon.

Very few adult burials have been found at Inamgaon, a point that Lukacs and Walimbe (1984:111-112) attributed to the better preservation of infants buried in the relatively more protective environment of the urns, as well as differential treatment at death according to age group. They argued that adult skeletons were more likely to deteriorate and that it is also likely that some adults were buried offsite or possibly treated in other ways such as exposure or cremation combined with the disposal of ashes in the nearby river (Lukacs and Walimbe 1984:111). There were few non-urn burials at Inamgaon and only two, both children, were from the Malwa period; the oldest identified age at death, 10 years, is represented by one skeleton. However, 11 percent of skeletons from the Early Jorwe period and 23 percent of skeletons from the Late Jorwe period have been identified as age 10 and older. ${ }^{6}$ Thus, beginning in the Early Jorwe and continuing in the Late Jorwe, we see burials of teens as well as adults in the habitation area, a statistically significant change in burial practices over time at Inamgaon. The contrast of continuity of infant burial practices and change in subadult and adult burial practices is noteworthy. The introduction of adult burials may indicate that age was no longer marked through location of interment. This may, in turn, reflect changing conceptions of age as an aspect of personhood among the living.

\section{DISCUSSION}

The archaeological evidence suggests that change in subsistence strategies occurred in the Late Jorwe period. Dhavalikar (1984) and Shinde (1994) argued that subsistence practices shifted away from growing grains and toward pastoralism and hunting. This subsistence change necessitated transformations of work patterns, organization of social groups, and location of work. As agricultural pursuits decreased, time spent working animals, seeking pastureland, hunting, or gathering increased. Greater mobility may have led to the division of a previously cohesive settlement for long periods of time. Work groups may have been reorganized in order to meet the demands of new modes of food acquisition. Together, these changes represent a fundamental restructuring of a way of life, with enormous repercussions for social organization.

Panja's model in which hunter-gatherer groups began to cohabitate with the original residents at Inamgaon, also suggests broader social repercussions. In addition to the reorganization of work groups, as mentioned above, new economic patterns, based on trade and exchange of wild food for other items, may have been established. In turn, this may have prompted changes in craft production and organization. New residents at Inamgaon may have had their own distinct set of practices that would have affected how common space and common resources were utilized and shared. New social relationships within the settlement may have formed as existing ones were redefined.

Within this framework of altered subsistence strategies and social networks, infant burial practices between the Early and Late Jorwe at Inamgaon demonstrate marked continuity. The practice of burying infants in single and double urns continued, as did the practice of placing the body in a north-south direction, with 
the upper body in the northern urn. There is also indication that people of the Late Jorwe actively maintained the tradition of using Red/Gray Ware burial urns, even as they discontinued the use of this fabric in the general ceramic assemblage.

Continuity in infant burial practices in the Late Jorwe at Inamgaon contrasts with subsistence transformation. We know that significant change in everyday social practices must have occurred since the acts of procuring and preparing food changed dramatically. In both scenarios, social practices, including those related to subsistence, exchange, and social organization, changed dramatically. At Inamgaon, the socially significant practice of infant burial was actively constituted in similar ways throughout all three periods of time. However, in later periods, this method of interring infants began to disappear entirely at other sites in the region, as demonstrated at Chandoli and Nasik. The discontinuation of this practice at other sites may indicate that the treatment of infants at death became more similar to that of adults. While it is not possible to speculate on the reasons for this change, it is clear that the residents of these sites did not follow the course of Inamgaon in which infant burial practices were actively retained.

This contrast between punctuated burial practices and daily subsistence practices may indicate a desire to uphold meaningful traditions during a time of great social change. Maintenance of meaningful rituals balanced changes in daily activities. The death of a family member, even an infant, may have forced mourners to confirm and reconfirm their beliefs about death and how life should be lived. Mourners thus prepared the body, taking care to perform the rituals "correctly," that is, in the traditional way. Upholding old traditions during times of crisis had the potential to offer comfort to those in mourning. While change was tolerated in everyday life, new ideas may not have been tolerated for significant practices in the ideational realm. This is not to say that burial tradition was rigid at Inamgaon. On the contrary, families were able to personalize these traditions, changing one or more variable, such as urn orientation or the inclusion of grave goods, while upholding standard practices in the rest of the burial.

How, then, can increasing numbers of adult burials over time at Inamgaon be explained? The major shift toward onsite burial of adults occurred between the Malwa and Early Jorwe periods before the subsistence changes began. By the end of the Early Jorwe period, the practice of adult burial within the settlement had stabilized and continued at similar rates through the Late Jorwe. Burying deceased adults on-site, in similar locations as infants, downplays age as an aspect of personhood. While adult status is still marked by method of interment, it is not marked by location of interment. Interestingly, change in location occurs in adults, not infants. While reconceptualization of adult status occurred, possibly among the living as well as the dead, similar changes did not occur among infants. Conceptions of early childhood and what it meant to be an infant may have been actively upheld even as conceptions of adulthood changed and as larger social practices changed.

\section{CONCLUSION}

While Dhavalikar and Panja argued for dramatic change at Inamgaon in the Late Jorwe, each in their own way, burial analysis reveals a complex picture of both continuity and change. Conservation of burial practices or traditions may 
have been a response to major changes in daily routines and served to stabilize them. The fluidity that existed within the body of social practices at Inamgaon allowed individual, familial, or group expression to vary from the norm even as it reconfirmed it. While subsistence studies help provide a general picture of how a society operated, a study of burial practices reveals the parallel complexity that exists in deeper traditions. Moreover, by examining contemporaneous variability of burial practices it is possible to see persons in the archaeological record. It is the combination of the general context (subsistence) with particulars about persons (burials) that offers a complete picture of society 3000 years ago.

\section{ACKNOWLEDGMENTS}

Several people have been tremendously helpful in the process of writing this piece. I would like to thank Peter Johansen and Namita Sugandhi for inviting me to participate in the initial session at the 2001 SAAs and for their critical assistance in the review process. I would also like to thank Professor Shinde for answering my questions about the Deccan Chalcolithic; Gregory Possehl, Kathy Morrison, Jim Shaffer, John Lukacs, Miriam Stark, and two anonymous reviewers for their advice and insight. Of course, any misunderstandings and shortcomings remain my own.

\section{NOTES}

1. These numbers reflect instances of burials. The actual number of skeletons recovered varies from these numbers since some burial urns contained no human remains and others contained more than one. For the purposes of this analysis I have considered one urn (or double urn or triple urn) to be one burial and one non-urn skeleton to be a burial.

2. Localized hypoplasia of primary canine teeth is an enamel defect that occurs in primary teeth usually due to poor nutrition during infancy and early childhood (Skinner et al. 1994). It is considered to be a more specific marker of nutritional stress than linear enamel hypoplasia, which can occur in adults as well.

3. This particular comparison only included twin urn and extended burials since there were insufficient numbers of teeth from single urn and "sarcophagus burials."

4. Details on some burials were not included in the site report. Thus this analysis includes only a portion of burials retrieved from the site.

5. Unfortunately, many burial summaries did not include the type of ceramic from which the urn was made. Of those that were reported, a majority of burial urns of all periods were made of Red/Gray Ware. Dhavalikar and Ansari mention that Red/Gray Ware continues to be the favored ceramic of burial urns (Dhavalikar and Ansari 1988c:263). However, without a full account of every burial urn, this trend should be considered suggestive and not definitive.

6. These burials are non-urn burials. The increase of adult burials is considered significant based on the application of a chi-square test; chi-square $=16.69$, degrees of freedom $=2$, probability is less than or equal to .001 .

\section{REFERENCES CITED}

ANSARI, Z. D.

1988 Chronology, in Excavations at Inamgaon, vol. I, pt. i: 133-135, ed. M. K. Dhavalikar, H. D. Sankalia, Z. D. Ansari. Pune: Deccan College Postgraduate and Research Institute.

Barrett, J. C.

1996 The living, the dead and the ancestors: Neolithic and Early Bronze Age mortuary practices, in Contemporary Archaeology in Theory: A Reader: 394-412, ed. R. W. Preucel and I. Hodder. Oxford: Blackwell Publishers, Inc.

2000 A thesis on agency, in Agency in Archacology: 61-68, ed. M.-A. Dobres and J. Robb. London and New York: Routledge. 
BINFORD, L. R.

1971 Mortuary practices: Their study and potential, in Approaches to the Social Dimensions of Mortuary Practices: 6-29, ed. J. A. Brown. Society of American Archaeology Memoirs 25. Washington, D.C.: Society for American Archaeology.

Bopardikar, B. P.

1996 Excavations at Tuljapur Garhi 1984-85 (Vidarbha, Maharashtra). Memoirs of the Archaeological Survey of India 95. New Delhi: Archaeological Survey of India.

Bourdieu, P

1977 Outline of a Theory of Practice. Cambridge: Cambridge University Press.

Buikstra, J. E., And L. W. KonigsberG

1985 Paleodemography: Critiques and controversies. American Anthropologist 87:316-333.

Chakrabarti, D. K.

1999 India: An Archaeological History: Palacolithic Beginnings to Early Historic Foundations. New Delhi: Oxford University Press.

Chapman, J.

2000 Tension at funerals: social practices and the subversion of community structure in later Hungarian prehistory, in Agency in Archaeology: 169-195, ed. M.-A. Dobres and J. Robb. London and New York: Routledge.

Cowgill, G. L.

2000 "Rationality" and contexts in agency theory, in Agency in Archaeology: 51-60, ed. M.-A. Dobres and J. Robb. London and New York: Routledge.

Deavaraj, D. V., J. G. Shaffer, C. S. Patil, and Balasubramanya

1995 The Watgal excavations: An interim report. Man and Environment 20:57-74.

DEO, S. B.

1969 Songaon Excavation 1965. Pune: Deccan College Postgraduate and Research Institute.

Deo, S. B., AND Z. D. ANSARI

1965 Chalcolithic Chandoli. Pune: Deccan College Postgraduate and Research Institute.

DHAVALIKAR, M. K.

1979 Early farming cultures of Deccan, in Essays in Indian Protohistory: 247-265, ed. D. P. Agrawal and D. K. Chakrabarti. Delhi: B. R. Publishing Corporation.

1984 Toward an ecological model for Chalcolithic cultures of central and western India. Journal of Anthropological Archaeology 3:133-158.

1985 Chalcolithic Cultures: A socio-economic perspective, in Archaeological Perspective of India Since Independence: 63-80, ed. K. N. Dikshit. New Delhi: Indian Archaeological Society.

1988 Inamgaon: A Chalcolithic chiefdom, in Excavations at Inamgaon, vol. 1, pt ii: 1001-1008, ed. M. K. Dhavalikar, H. D. Sankalia, and Z. D. Ansari. Pune: Deccan College Postgraduate and Research Institute.

Dhavalikar, M. K., And Z. D. Ansari

1988a Structures, in Excavations at Inamgaon, vol. 1, pt. i: 137-262, ed. M. K. Dhavalikar, H. D. Sankalia, and Z. D. Ansari. Pune: Deccan College Postgraduate and Research Institute.

1988b) Pottery, in Excavations at Inamgaon, vol. 1, pt. i: 341-503, ed. M. K. Dhavalikar, H. D. Sankalia, and Z. D. Ansari. Pune: Deccan College Postgraduate and Research Institute.

1988 c Burials, in Excavations at Inamgaon, vol. 1, pt. i: 263-340, ed. M. K. Dhavalikar, H. D Sankalia, and Z. D. Ansari. Pune: Deccan College Postgraduate and Research Institute.

Dhavalikar, M. K., H. D. Sankalia, and Z. D. Ansari

1988 Exavations at Inamgaon, vol. 1, pt. i-ii. Pune: Deccan College Postgraduate and Research Institute.

Dhavalikar, M. K., V. S. Shinde, and S. Atre

1990 Small site archaeology: Excavations at Walki. Bulletin of the Deccan College Post-Graduate and Research Institute 50:197-228.

Giddens, A

1984 The Constitution of Society: Outline of a Theory of Structuration. Berkeley and Los Angeles: University of California Press. 
Gillespie, S. D.

2001 Personhood, agency, and mortuary ritual: A case study from the ancient Maya. Journal of Anthropological Archaeology 20:73-112.

Hertz, R.

1960 Death and the Right Hand, trans. R. Needham and C. Needham. New York: Free Press.

Kajale, M. D., G. L. Badam, and S. N. Rajaguru

1976 Late Quaternary history of the Ghod Valley, Maharashtra. Geophytology 6(1):122-132.

Kale, V. S., and S. N. Rajaguru

1987 Late Quaternary alluvial history of the northwestern Deccan upland region. Nature $325: 612-614$.

Kennedy, K.A.R., And K. C. Malhotra

1966 Human Skeletal Remains from Chalcolithic and Indo-Roman Levels from Nevasa: An Anthropometric and Comparative Analysis. Pune: Deccan College Postgraduate and Research Institute.

Konigsberg, L. W., and S. R. Frankenberg

1994 Paleodemography: "Not Quite Dead." Evolutionary Anthropology 3(3) : 92-105.

Korisettar, R., P. C. Venkatasubbaiah, and D. Q. Fuller

2002 Brahmagiri and beyond: The archaeology of the southern Neolithic, in Indian Archaeology in Retrospect: Prehistory, vol. 1, Archaeology of South Asia: 151-237, ed. S. Settar and R. Korisettar. New Delhi: Indian Council of Historical Research.

Krishnamurthy, R. V., D. P. Agrawal, V. N. Misra, and S. N. Rajaguru

1981 Paleoclimatic inferences from the behavior of radiocarbon dates of carbonates from sand dunes of Rajasthan. Proceedings of the Indian Academy of Science (Earth and Planetary Sciences) 90(2) : 155-160.

LUKACS, J. R., AND G. L. BADAM

1976- Biological anthropology of human skeletal remains from Chalcolithic Inamgaon, western

1977 India. Bulletin of the Deccan College Research Institute 36(1-4): 73-83.

Lukacs, J. R., G. C. Nelson, S. R. Walimbe

2001 Enamel hypoplasia and childhood stress in prehistory: new data from India and Southwest Asia. Journal of Archaeological Science 28(11):1159-1169.

Lukacs, J. R., AND S. R. WALimbe

1984 Paleodemography at Inamgaon: An early farming village in western India, in The People of South Asia: The Biological Anthropology of India, Pakistan, and Nepal: 105-132, ed. J. R. Lukacs. New York: Plenum Press.

1986 Excavations at Inamgaon, vol. 2, The Physical Anthropology of Human Skeletal Remains: An Osteobiogeographic Analysis. Pune: Deccan College Postgraduate and Research Institute.

1998 Physiological stress in prehistoric India: New data on localized hypoplasia of primary canines linked to climate and subsistence change. Journal of Archaeological Science $25(6): 571-585$.

2000 Health, climate, and culture in prehistoric India: Conflicting conclusions from archaeology and anthropology? South Asian Archaeology 1997, vol. 2:363-381, ed. M. Taddei. Naples: IsMEO.

McHugh, F.

1999 Theoretical and Quantitative Approaches to the Study of Mortuary Practice. BAR International Series 785. Oxford: Archaeopress.

Metcalf, P., and R. Huntington

1991 Celebrations of Death: The Anthropology of Mortuary Ritual. Cambridge: Cambridge University Press.

MORRISON, K. D.

2002 Historicizing adaptation, adapting to history: Forager-traders in South and Southeast Asia, in Forager-Traders in South and Southeast Asia, ed. K. D. Morrison and L. L. Junker. New York: Cambridge University Press.

Mushrif, V., and S. R. Walimbe

2000 A fresh look at the human skeletal remains from Chalcolithic Walki (Maharashtra). Man and Enviromment 25(2): 19-24. 
Nagaraja RaO, M. S.

1971 Protohistoric Cultures of the Tungabhadra Valley (a report on Hallur Excavations). Dharwar.

Nagaraja Rao, M. S., and K. C. Malhotra

1965 The Stone Age Duellers of Tekkalakota. Pune: Deccan College Postgraduate and Research Institute.

NAIK, S., AND S. Mishra

1997 The Chalcolithic phase in the Bhima Basin, Maharashtra: A review. Man and Environment $22(1): 45-58$.

O'SHEA, J.

1981 Social configurations and the archaeological study of mortuary practices: A case study, in The Archaeology of Death: 39-52, ed. R. Chapman, I. Kinnes, and K. Randsborg. Cambridge: Cambridge University Press.

PANJA, S

1999 Mobility and subsistence strategies: a case study of Inamgaon, a Chalcolithic site in western India. Asian Perspectives 38(2): 154-185.

2002 Research on the Deccan Chalcolithic, in Indian Archaeology in Retrospect: Prehistory, vol. 1, Archaeology of South Asia: 263-276, ed. S. Settar and R. Korisettar. New Delhi: Indian Council of Historical Research.

PAWANKAR, S.

1996 Man and Animal Relationship in the Early Farming Communities of Western India with Special Reference to Inamgaon. Unpublished Ph.D. diss. Pune: University of Poone.

Pearson, M. Parker

1999 The Archaeology of Death and Burial. College Station: Texas A \& M University Press.

Possehl, G. L.

1976 Lothal: A gateway settlement of the Harappan civilization, in Ecological Backgrounds of South Asian Prehistory: 118-131, ed. K.A.R. Kennedy and G. L. Possehl. Cornell University South Asia Program, Occasional Papers and Theses No. 4. Ithaca, NY.

2002 Harappans and hunters: Economic interaction and specialization in prehistoric India, in Forager-Traders in South and Southeast Asia: Long Term Histories: 62-76, ed. K. D. Morrison and L. L. Junker. New York: Cambridge University Press.

PARAsher, A., AND Mira RaI

1984 The character of the neolithic chalcolithic settlement patterns in northern Deccan. Proceedings_-Indian History Congress 45:872-881.

RAMI REDDY, V.

1976 The Prehistoric and Protohistoric Cultures of Palavoy, South India: with Special Reference to the Ashmound Problem. Hyderabad: Government of Andhra Pradesh.

SALI, S. A.

1986 Daimabad 1976-79. Memoirs of the Archaeological Survey of India 83. New Delhi: Archaeological Survey of India.

SANKalia, H. D.

1964 Stone Age hill dwellers of South India: Excavations at Tekkalakota, Bellary Dist. Mysore State. Indica 1, 2:129-40.

Sankalia, H. D., S. B. Deo, Z. D. Ansari, and S. Ehrhardt

1960 From History to Pre-history at Nevasa, (1954-56). Pune: Deccan College Postgraduate and Research Institute.

SCHEPER-Hughes, N.

1992 Deatl Without Weeping: The Violence of Everyday Life in Brazil. Berkeley and Los Angeles: University of California Press.

SHINDE, V.

1988 New light on the origin, settlement system and decline of the Jorwe Culture of the Deccan, India. South Asian Studies 5:59-72.

1989 The Malwa Culture in Maharashtra: A study of settlement and subsistence patterns. Man and Enviromment 15(2):53-60.

1990 Craft specialization and social organization in the Chalcolithic Deccan, India. Antiquity $65: 796-807$. 
1994 The Deccan Chalcolithic: A recent perspective. Man and Environment 19(1-2): 169-177.

Shinde, V., AND R. PAPPU

1990 Daimabad: The Chalcolithic regional centre in the Godavari Basin Bulletin of the Deccan College Postgraduate and Research Institute 50:307-316.

Skinner, M. F., W. Hadaway, and J. Dickie

1994 Effects of ethnicity and birth month on localized enamel hypoplasia of the primary canine. Journal of Dentistry for Children 61(3): 109-113.

Subrahmanyam, R.

1975 Nagarjunakonda (1954-60), vol. 1. Memoirs of the Archaeological Survey of India 75. New Delhi: Archaeological Survey of India.

WALIMBE, S. R.

1996 Human skeletal evidence from Chalcolithic Tuljapur Garhi, in Excavations at Tuljapur Garhi 1984-85: 43-46, ed. B. P. Bopardikar. New Delhi: Archaeological Survey of India.

WHEELER, R.E.M.

1948 Brahmagiri and Chandravalli 1947: Megalithic and other cultures in Mysore State. Ancient India $4: 180-310$.

\begin{abstract}
Shifts in subsistence strategies during the transition between Early Jorwe (14001000 в.с.) and Late Jorwe (1000-700 B.C.) periods of the western Deccan region of India have been the focus of much archaeological research. This article reviews the various theories proposed by researchers to explain transformations in subsistence practices at this time and suggests that these changes had multiple repercussions in the realm of social organization. These changes contrast markedly with a continuity in infant burial practices. Reconfirming burial traditions may have served to counterbalance the changes that occurred in daily practices. Even though burial practices were upheld over time, individuals and groups varied slightly in their interpretation of burial tradition, as well as their desire and ability to perform burial rites according to tradition. Keywords: subsistence, burial practices, Chalcolithic, India, Deccan.
\end{abstract}

